\title{
CORRECTION
}

\section{Correction to: Intercalary bone graft of the tibia: case series and review of the literature}

\author{
Claudio Giannini ${ }^{1} \cdot$ Andrea Sambri $^{2,3}$ (1) Mattia Dalla Rosa ${ }^{1} \cdot$ Riccardo Zucchini $^{1} \cdot$ Valerio Bochicchio $^{3}$.
} Michele Fiore $^{1} \cdot$ Davide Maria Donati $^{1,2} \cdot$ Massimiliano De Paolis $^{3}$

Published online: 10 July 2020

(c) Springer-Verlag France SAS, part of Springer Nature 2020

\section{Correction to: \\ European Journal of Orthopaedic Surgery \& Traumatology https://doi.org/10.1007/s00590-020-02718-y}

The original version of this article unfortunately contained a mistake. The spelling of the name 'Valerio Bochicchio' was incorrect.

Publisher's Note Springer Nature remains neutral with regard to jurisdictional claims in published maps and institutional affiliations.

The original article can be found online at https://doi.org/10.1007/ s00590-020-02718-y.

\footnotetext{
Andrea Sambri andrea_sambri@libero.it

1 IRCCS Istituto Ortopedico Rizzoli, Bologna, Italy

2 University of Bologna, Bologna, Italy

3 AOU Sant'Orsola-Malpighi, Via Massarenti 9, Bologna, Italy
} 